\title{
Effects of different dietary DHA:EPA ratios on gonadal steroidogenesis in the marine teleost, tongue sole (Cynoglossus semilaevis)
}

\author{
Houguo $\mathrm{Xu}^{1}$, Lin $\mathrm{CaO}^{1}$, Yuliang $\mathrm{Wei}^{1}$, Yuanqin Zhang $^{1}$ and Mengqing Liang ${ }^{1,2 *}$ \\ ${ }^{1}$ Yellow Sea Fisheries Research Institute, Chinese Academy of Fishery Sciences, 106 Nanjing Road, Qingdao 266071, \\ People's Republic of China \\ ${ }^{2}$ Laboratory for Marine Fisheries Science and Food Production Processes, Qingdao National Laboratory for Marine Science \\ and Technology, 1 Wenhai Road, Qingdao 266237, People's Republic of China
}

(Submitted 11 May 2017 - Final revision received 28 June 2017 - Accepted 28 June 2017)

\section{Abstract}

The present study was conducted to investigate the effects of dietary DHA and EPA on gonadal steroidogenesis in mature females and males, with a feeding trial on tongue sole, a typical marine teleost with sexual dimorphism. Three experimental diets differing basically in DHA:EPA ratio, that is, 0.68 (diet D:E-0.68), 1.09 (D:E-1.09) and 2.05 (D:E-2.05), were randomly assigned to nine tanks of 3-year-old tongue sole (ten females and fifteen males in each tank). The feeding trail lasted for $90 \mathrm{~d}$ before and during the spawning season. Fish were reared in a flowing seawater system and fed to apparent satiation twice daily. Compared with diet D:E-0.68, diet D:E-1.09 significantly enhanced the oestradiol production in females, whereas diet D:E-2.05 significantly enhanced the testosterone production in males. In ovaries, diet D:E-1.09 induced highest mRNA expression of follicle-stimulating hormone receptor (FSHR), steroidogenic acute regulatory protein, $17 \alpha$-hydroxylase

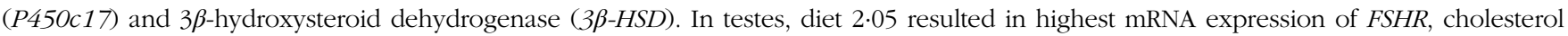
side-chain cleavage enzyme, $P 450 c 17$ and $3 \beta-H S D$. Fatty acid profiles in fish tissues reflected closely those of diets. Female fish had more gonadal EPA content but less DHA content than male fish, whereas there was a reverse observation in liver. In conclusion, the dietary DHA: EPA ratio, possibly combined with the dietary EPA:arachidonic acid ratio, differentially regulated sex steroid hormone synthesis in mature female and male tongue soles. Females seemed to require more EPA but less DHA for the gonadal steroidogenesis than males. The results are beneficial to sex-specific nutritive strategies in domestic teleost.

Key words: Cynoglossus semilaevis: Diets: DHA: EPA: Sex steroid hormone synthesis

DHA (22:6n-3) and EPA (20:5n-3), the so-called $n$-3 longchain PUFA (LC-PUFA), have been reported to play important roles in reproductive performances of animals ${ }^{(1,2)}$, especially marine fish ${ }^{(3-13)}$, which require LC-PUFA as essential fatty acids $^{(14)}$. However, despite the wide studies on the effects of $n-3$ LC-PUFA on animal reproduction, little information has been published about the different effects between DHA and EPA. The present study was aimed at investigating the different efficacy between DHA and EPA in regulating reproductive processes, in a typical marine teleost, tongue sole (Cynoglossus semilaevis).

In animal reproduction, synthesis of sex steroid hormones is one of the most primary processes ${ }^{(15)}$. Steroid hormones activate the gonadal development and play important regulating roles all through the reproductive period, even including ovulation $^{(16)}$. Compared with spawning performance and offspring quality, the regulation of steroid hormones by fatty acids has been relatively neglected, although a few studies have investigated the interactions between body fatty acid accumulation and steroid production ${ }^{(17,18)}$. Therefore, the present study focused on the regulatory effects of DHA and EPA on steroid hormone synthesis. In both terrestrial animals and fish species, less information has been available about the modulation of steroidogenesis by DHA and EPA ${ }^{(19-22)}$. Moreover, contradictory results have been reported in fish studies $^{(23-26)}$. The present study will provide new insight into the regulatory effects of DHA and EPA on animal gonadal steroidogenesis. The regulation on key proteins involved in the key processes of sex steroid synthesis, that is, the response to gonadotrophins, the delivery of cholesterol substrate and biosynthetic reactions, in terms of gene expressions, was also investigated in this study, in order to elucidate the involved mechanisms.

In a previous study of our laboratory with tongue sole (C. semilaevis), we have studied the response of gonadal steroidogenesis to arachidonic acid (ARA, C20:4n-6), the most

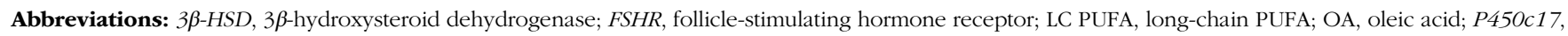

$17 \alpha$-hydroxylase; StAR, steroidogenic acute regulatory protein; TFA, total fatty acids.

* Corresponding author: M. Liang, fax +86 5328 5822914, email liangmq@ysfri.ac.cn 
important n-6 LC-PUFA ${ }^{(27)}$. We found that dietary ARA was differentially accumulated in gonads and differentially regulated the gonadal steroidogenesis depending on fish sex and maturation stage. Interestingly, in this study, we found that DHA and EPA were also differentially accumulated between ovaries and testis. Therefore, as a follow-up study, the present study investigated the different effects of DHA:EPA on gonadal steroidogenesis between females and males. Tongue sole is a typical fish with sexual dimorphism. The females are several times bigger than males, making it a perfect species to study the sex-based difference in animal nutrition. This study will provide useful information for sex-specific nutritive strategies in domestic teleost, and these nutritive strategies may also be inspiring for other animals.

\section{Methods}

\section{Experimental diets}

Three isonitrogenous and isolipidic experimental diets were formulated to contain different levels of DHA:EPA ratio (Table 1). The basal diet was formulated using fishmeal, casein and wheat meal as protein sources, and soya lecithin, soyabean oil and olive oil as lipid sources. Different levels of EPA-enriched oil (containing $11.2 \% \mathrm{DHA}$ and $52.0 \% \mathrm{EPA}$, in the form of TAG; Xi'an Renbang Biological Science and Technology Co., Ltd) and DHA-enriched oil (containing 69.5\% DHA and 6.6\% EPA, in the form of TAG; Xi'an Renbang Biological Science and Technology Co., Ltd) were added to the basal diet to obtain different DHA: EPA ratios. The diets were made, packed and stored according to the standard procedures in our laboratory ${ }^{(28)}$. The DHA:EPA ratio in the three experimental diets was $0.68,1.09$ and 2.05, respectively (Table 2). The corresponding diets were designated as D:E-0.68, D:E-1.09 and D:E-2·05, respectively.

\section{Experimental fish and feeding procedure}

Tongue sole C. semilaevis broodstock, 3-years old, which have been reared with formulated feeds from the early juvenile stage, were used in the present study. The average initial body weight of females and males was 3206 and $253 \mathrm{~g}$, respectively. Before the start of the feeding trial, experimental fish were reared in concrete tanks $\left(25 \mathrm{~m}^{3}\right)$ and fed the control diet for $7 \mathrm{~d}$ to acclimate to the experimental conditions. At the onset of the feeding trial, experimental fish were distributed into nine polyethylene tanks (diameter: $230 \mathrm{~cm}$, height: $100 \mathrm{~cm}$ ) and each diet was randomly assigned to triplicate tanks. Each tank had twenty-five fish (ten females and fifteen males) and the tanks were supplied with flowing filtered seawater at a rate of 50 litre/min. Fish were hand-fed to apparent satiation twice daily. The feeding trial lasted for $90 \mathrm{~d}$, from July to October, which is the natural spawning season of tongue sole. Fish were reared under the natural photoperiod and ambient temperature of Haiyang, Shandong, China (N36 $\left.41^{\prime}, \mathrm{E} 121^{\circ} 07^{\prime}\right)$. During the experiment, the water temperature ranged from 20 to $26^{\circ} \mathrm{C}$; salinity was 30-32; $\mathrm{pH}$ was 7.4-8.5; and dissolved $\mathrm{O}_{2}$ was $5-7 \mathrm{mg} / \mathrm{l}$. The ponds were cleaned daily by siphoning out residual feed and faeces.
Table 1. Formulation and proximate composition of the experimental diets (g/kg DM)

\begin{tabular}{|c|c|c|c|}
\hline Ingredients & D:E-0.68 & D:E-1.09 & D:E-2.05 \\
\hline Fishmeal & $580 \cdot 0$ & $580 \cdot 0$ & $580 \cdot 0$ \\
\hline Casein & $140 \cdot 0$ & $140 \cdot 0$ & $140 \cdot 0$ \\
\hline Wheat meal & 144.5 & 144.5 & 144.5 \\
\hline Vitamin premix* & $10 \cdot 0$ & $10 \cdot 0$ & $10 \cdot 0$ \\
\hline Mineral premix $†$ & $10 \cdot 0$ & $10 \cdot 0$ & $10 \cdot 0$ \\
\hline Monocalcium phosphate & $10 \cdot 0$ & $10 \cdot 0$ & $10 \cdot 0$ \\
\hline Choline chloride & $10 \cdot 0$ & $10 \cdot 0$ & $10 \cdot 0$ \\
\hline L-Ascorbyl-2-polyphosphate & $5 \cdot 0$ & $5 \cdot 0$ & $5 \cdot 0$ \\
\hline Ethoxyquin & 0.5 & 0.5 & 0.5 \\
\hline Soya lecithin & $20 \cdot 0$ & $20 \cdot 0$ & $20 \cdot 0$ \\
\hline Soyabean oil & $15 \cdot 0$ & $15 \cdot 0$ & $15 \cdot 0$ \\
\hline ARA-enriched oilł & $6 \cdot 0$ & $6 \cdot 0$ & $6 \cdot 0$ \\
\hline Olive oil & $19 \cdot 1$ & $20 \cdot 7$ & $22 \cdot 3$ \\
\hline EPA-enriched oil§ & $27 \cdot 6$ & $17 \cdot 7$ & $7 \cdot 8$ \\
\hline DHA-enriched oilll & $2 \cdot 3$ & $10 \cdot 6$ & $18 \cdot 9$ \\
\hline \multicolumn{4}{|l|}{ Proximate composition } \\
\hline Crude protein & $576 \cdot 2$ & $579 \cdot 0$ & 578.9 \\
\hline Crude lipid & $125 \cdot 5$ & $125 \cdot 8$ & $125 \cdot 0$ \\
\hline Ash & 141.4 & $135 \cdot 8$ & 141.5 \\
\hline
\end{tabular}

ARA, arachidonic acid.

* Vitamin premix (mg or g/kg diet): thiamin, $25 \mathrm{mg}$; riboflavin, $45 \mathrm{mg}$; pyridoxine $\mathrm{HCl}$, $20 \mathrm{mg}$; vitamin $\mathrm{B}_{12}, 0.1 \mathrm{mg}$; vitamin $\mathrm{K}_{3}, 10 \mathrm{mg}$; inositol, $800 \mathrm{mg}$; pantothenic acid, $60 \mathrm{mg}$; niacin, $200 \mathrm{mg}$; folic acid, $20 \mathrm{mg}$; biotin, $1.2 \mathrm{mg}$; retinol acetate, $32 \mathrm{mg}$; cholecalciferol, $5 \mathrm{mg}$; $a$-tocopherol, $120 \mathrm{mg}$; wheat middling, $13.67 \mathrm{~g}$.

† Mineral premix (mg or g/kg diet): $\mathrm{MgSO}_{4} .7 \mathrm{H}_{2} \mathrm{O}, 1200 \mathrm{mg}$; $\mathrm{CuSO}_{4} .5 \mathrm{H}_{2} \mathrm{O}, 10 \mathrm{mg}$; $\mathrm{ZnSO}_{4} \cdot \mathrm{H}_{2} \mathrm{O}, 50 \mathrm{mg} ; \mathrm{FeSO}_{4} \cdot \mathrm{H}_{2} \mathrm{O}, 80 \mathrm{mg} ; \mathrm{MnSO}_{4} \cdot \mathrm{H}_{2} \mathrm{O}, 45 \mathrm{mg} ; \mathrm{CoCl}_{2} \cdot 6 \mathrm{H}_{2} \mathrm{O}(1 \%)$, $50 \mathrm{mg} ; \mathrm{NaSeSO}_{3} \cdot 5 \mathrm{H}_{2} \mathrm{O}(1 \%), 20 \mathrm{mg} ; \mathrm{Ca}\left(\mathrm{IO}_{3}\right)_{2} \cdot 6 \mathrm{H}_{2} \mathrm{O}(1 \%), 60 \mathrm{mg}$; zoelite, $13.485 \mathrm{~g}$.

‡ ARA-enriched oil: containing $41.0 \%$ ARA (of total fatty acids), in the form of TAG; Jiangsu Tiankai Biotechnology Co., Ltd.

§ EPA-enriched oil: containing $11.2 \%$ DHA and $52.0 \%$ EPA (of total fatty acids), in the form of TAG; Xi'an Renbang Biological Science and Technology Co., Ltd. ॥ DHA-enriched oil: containing 69.5\% DHA and 6.6\% EPA (of total fatty acids), in the form of TAG; Xi'an Renbang Biological Science and Technology Co., Ltd.

Table 2. Fatty acid compositions of the experimental diets (\% total fatty acids)

\begin{tabular}{|c|c|c|c|}
\hline Fatty acids & D:E-0.68 & D:E-1.09 & D:E-2.05 \\
\hline C14:0 & $2 \cdot 1$ & 2.4 & $2 \cdot 1$ \\
\hline C16:0 & $14 \cdot 6$ & $16 \cdot 5$ & $15 \cdot 5$ \\
\hline C18:0 & 4.4 & 4.7 & 4.5 \\
\hline$\sum S F A$ & 21.0 & 23.6 & $22 \cdot 1$ \\
\hline C16:1n-7 & $2 \cdot 1$ & 2.4 & $2 \cdot 2$ \\
\hline C18: $1 n-9$ & $20 \cdot 4$ & 21.8 & 22.5 \\
\hline C18:1n-7 & 2.4 & 2.4 & $2 \cdot 2$ \\
\hline$\sum$ MUFA & 24.9 & $26 \cdot 6$ & $26 \cdot 9$ \\
\hline C18:2n-6 & $15 \cdot 6$ & $15 \cdot 7$ & $15 \cdot 9$ \\
\hline $\mathrm{C} 20: 4 n-6$ & $3 \cdot 8$ & 3.4 & $3 \cdot 2$ \\
\hline$\sum n-6$ PUFA & $19 \cdot 3$ & $19 \cdot 1$ & $19 \cdot 1$ \\
\hline C18:3n-3 & 1.9 & $1 \cdot 7$ & 1.8 \\
\hline $\mathrm{C} 20: 5 n-3$ & 14.5 & $10 \cdot 7$ & 7.5 \\
\hline $\mathrm{C} 22: 5 n-3$ & 1.5 & 1.8 & 2.4 \\
\hline $\mathrm{C} 22: 6 n-3$ & 9.9 & 11.7 & $15 \cdot 3$ \\
\hline$\sum n-3$ PUFA & $27 \cdot 7$ & $26 \cdot 0$ & $26 \cdot 9$ \\
\hline DHA:EPA & 0.7 & $1 \cdot 1$ & $2 \cdot 1$ \\
\hline$\sum n-3: \sum n-6$ & $1 \cdot 4$ & $1 \cdot 4$ & $1 \cdot 4$ \\
\hline
\end{tabular}

\section{Sampling}

At the end of the feeding trial, serum, liver, muscle and gonad samples from five mature females and five mature males per tank were collected. The maturity of female and male fish was confirmed by spontaneous ovulation and the release of milt 
when handled, respectively. After being anaesthetised with eugenol (1:10 000), blood was drawn from all fish via the caudal vein to collect serum samples. Fish were then dissected to collect liver, muscle and gonad samples. All samples were frozen with liquid $\mathrm{N}_{2}$ immediately, and then stored at $-80^{\circ} \mathrm{C}$ before analysis. All sampling protocols, as well as fish rearing practices, were reviewed and approved by the animal care and use committee of the Yellow Sea Fisheries Research Institute.

\section{Proximate composition analysis and fatty acid analysis}

The proximate composition analyses of experimental diets were performed in accordance with the standard methods of the Association of Official Analytical Chemists (AOAC). The fatty acid compositions of diet and fish tissue lipids were analysed via a gas chromatograph, using a flame ionisation detector. Fatty acids in freeze-dried samples were esterified first with $\mathrm{KOH}-$ methanol and then with $\mathrm{HCl}-$ methanol, on a $72^{\circ} \mathrm{C}$ water bath. Fatty acid methyl esters were extracted with hexane and then separated via gas chromatography (HP6890; Agilent Technologies Inc.) with a fused silica capillary column (007-CW; Hewlett Packard). The column temperature was programmed to rise from $150^{\circ} \mathrm{C}$ up to $200^{\circ} \mathrm{C}$ at a rate of $15^{\circ} \mathrm{C} / \mathrm{min}$, and then from $200^{\circ} \mathrm{C}$ to $250^{\circ} \mathrm{C}$ at a rate of $2^{\circ} \mathrm{C} / \mathrm{min}$. Both the injector and detector temperatures were $250^{\circ} \mathrm{C}$. Results were expressed as the percentage of each fatty acid with respect to total fatty acids (TFA).

\section{Quantitative real-time $P C R$ analysis and the analysis of oestradiol and testosterone in serum}

Total RNA in gonads was extracted using RNAiso Plus (TaKaRa Biotechnology (Dalian) Co., Ltd) and reverse-transcribed with PrimeScript ${ }^{\text {TM }}$ RT reagent Kit with gDNA Eraser (Perfect Real Time) (TaKaRa Biotechnology (Dalian) Co., Ltd) according to the user manual.

Specific primers for key proteins in steroidogenesis and the reference gene $\beta$-actin were designed on the basis of the sequences available in the GenBank database and synthesised by Sangon Biotech (Table 3). The real-time PCR was carried out with SYBR Green Real-time PCR Master Mix (TaKaRa Biotechnology (Dalian) Co., Ltd) in a quantitative thermal cycler (Mastercyclereprealplex; Eppendorf). The detailed program was similar to that of $\mathrm{Xu}$ et $a l .{ }^{(29)}$. The mRNA expression levels were studied by quantitative real-time PCR method: $2^{-\Delta \Delta C_{t}(30)}$.

Serum oestradiol and testosterone concentrations were assayed in collaboration with the affiliated hospital of Qingdao University, using an electrochemiluminescence method. COBAS-6000 (e 602 module) automatic electrochemiluminescence immunoassay analyzer (Roche Diagnostics) and affiliated commercial kits (Elecsys Estradiol III and Testosterone II) supplied by Roche were used in this assay. The standard curve for oestradiol was between 18.4 and $11010 \mathrm{pmol} / \mathrm{l}$, and for testosterone it was between 0.087 and $52 \mathrm{nmol} / \mathrm{l}$. To validate the assays for tongue sole, an assay of serial dilutions of various tongue sole plasma samples was conducted. The dilutions were found to be parallel to the standard assay curve. The validation of the recovery was also conducted by the assay of added steroids in tongue sole plasma. The recovery of oestradiol and
Table 3. Sequences of the primers used in this work

\begin{tabular}{|c|c|c|}
\hline Primers & Sequence (5'-3') & GenBank reference \\
\hline FSHR-F & AAGATCAAGGGAAAACGCTA & EU_661784.2 \\
\hline FSHR-R & CTCAGATGGTTGGAGGAAAG & \\
\hline StAR-F & ACCTCGTGGGTGACCATCGTGT & NM_001294220.1 \\
\hline StAR-R & AGGACGGCTGGACCACTGAAAT & \\
\hline P450ssc-F & TTCTGTGCTGTATGGCGAAC & GH_232539.1 \\
\hline P450ssc-R & CTTTTGACCCAATCCGTCTC & \\
\hline P450c17-F & GCCCACTCGCTCCCTACATACT & EU_580533.2 \\
\hline P450c17-R & GTCTTTCCCATCTCGGGTCAG & \\
\hline $3 \beta-H S D-F$ & CACCACTGGGTAAGCACTATC & XM_008328505.1 \\
\hline $3 \beta-H S D-\mathrm{R}$ & AGGTTATCGCAAACAGCATT & \\
\hline $17 \beta-H S D-F$ & AATGTGCAGGCTCTAACTGCTTC & XM_008330027.1 \\
\hline $17 \beta-H S D-\mathrm{R}$ & AGGTTCCTCATGGTGGCGTA & \\
\hline Aromatase-F & TGCGATTTCAGCCCGT & EF_134716.1 \\
\hline Aromatase- $\mathrm{R}$ & TGCGACCCGTGTTCAGA & \\
\hline$\beta$-Actin-F & TTGGCTCGTGTTCGTCGTTC & KP_033459.1 \\
\hline$\beta$-Actin-R & TCAGGGTGTTGGGCTTGTTG & \\
\hline
\end{tabular}

FSHR, follicle-stimulating hormone receptor; StAR, steroidogenic acute regulatory protein; P450ssc, cholesterol side-chain cleavage enzyme; P450c17, $17 a$-hydroxylase; $3 \beta-H S D, \quad 3 \beta$-hydroxysteroid dehydrogenase; $17 \beta-H S D$, $17 \beta$-hydroxysteroid dehydrogenase.

testosterone was $90.5 \%$ and $92.6 \%$, respectively. The steroid values were corrected for recovery losses. The inter- and intraassay CV for the oestradiol assay were $9 \cdot 3(n 7)$ and $4.3 \%(n 9)$, respectively, and those for the testosterone assay were $9.6(n 7)$ and $5.2 \%(n 9)$, respectively.

\section{Statistical methods}

All data were subjected to one-way ANOVA in SPSS 16.0 for Windows. All percentage data were arcsine transformed before analysis. Significant differences between the means were detected by Tukey's multiple-range test. The level of significance was chosen at $P<0 \cdot 05$. The results are presented as means of triplicate groups.

\section{Results}

\section{Concentrations of oestradiol and testosterone in serum}

In female fish, the oestradiol concentration in group D:E-0.68 was significantly $(P<0.05)$ lower than that in group D:E-1.09, whereas no significant difference was observed either between groups D:E-0.68 and D:E-2.05 or between groups D:E-1.09 and D:E-2.05 (Fig. 1(A)). In male fish, the testosterone concentration in group D:E-0.68 was significantly $(P<0.05)$ lower than that in group D:E-2.05, whereas no significant difference was observed either between groups D:E-0.68 and D:E-1.09 or between groups D:E-1.09 and D:E-2.05 (Fig. 1(B)).

\section{Gonadal mRNA expressions of sex steroid-synthesising proteins}

In mature ovaries (Fig. 2(A)), the mRNA expressions of folliclestimulating hormone receptor $(F S H R)$ and $17 \alpha$-hydroxylase (P450c17) were significantly higher $(P<0.05)$ in group D:E-1.09 than in the other two groups, whereas no significant difference was observed between the other two groups. The mRNA 

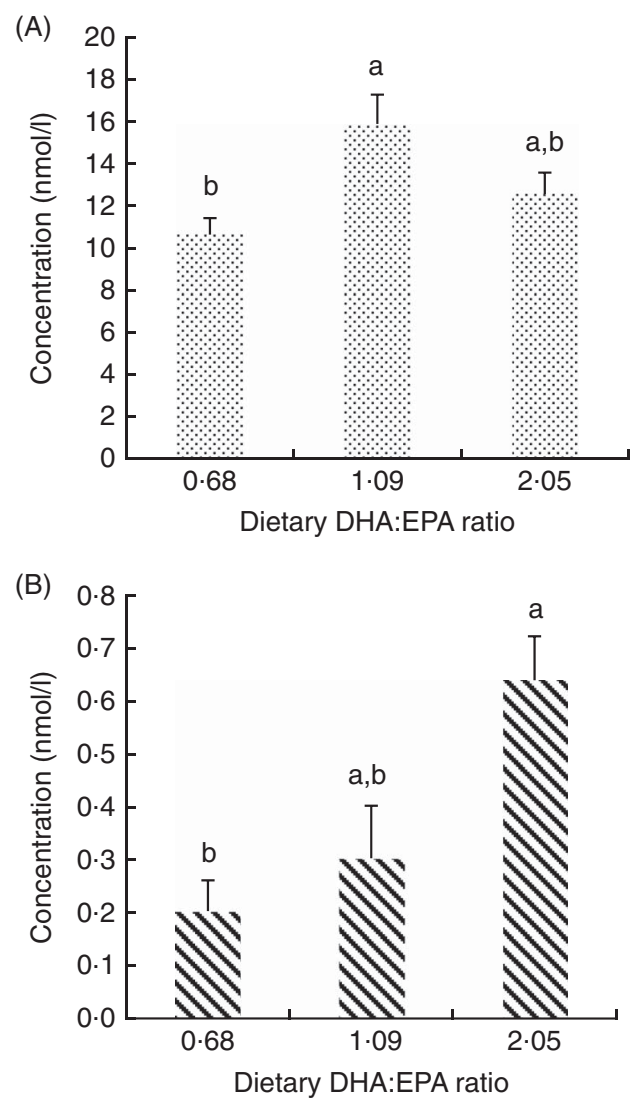

Fig. 1. Effects of dietary DHA:EPA ratios on the serum concentrations of oestradiol in females (A) and testosterone in males (B). Values are means of triplicate groups, with their standard errors represented by vertical bars. ${ }^{a, b}$ Mean values with unlike letters were significantly different $(P<0.05)$.

expressions of steroidogenic acute regulatory protein (StAR) and $3 \beta$-hydroxysteroid dehydrogenase $(3 \beta-H S D)$ in group D:E-1.09 were significantly higher $(P<0.05)$ than those in group D:E-0.68, whereas no significant difference was observed either between groups D:E-0.68 and D:E-2.05 or between groups D:E-1.09 and D:E-2.05. No significant difference was observed in mRNA expressions of cholesterol side-chain cleavage enzyme (P450ssc), 17 $\beta$-hydroxysteroid dehydrogenase (17 $\beta-H S D)$ and aromatase among dietary groups.

In mature testis (Fig. 2(B)), the mRNA expression of FSHR was significantly higher $(P<0.05)$ in group D:E-1.09 than in group D:E-0.68. The gene expression of P450ssc in group D:E-0.68 was significantly lower $(P<0.05)$ than that in groups D:E-1.09 and D:E-0.68, whereas no significant difference was observed between the latter groups. The mRNA expression of $P 450 c 17$ was the highest in group D:E-2.05, significantly higher $(P<0.05)$ than that in groups D:E-0.68 and D:E-1.09. The mRNA expression of $3 \beta-H S D$ was significantly higher in group D:E-2.05 compared with group D:E-0.68, whereas no significant difference was observed either between groups D:E-0.68 and D:E-1.09 or between groups D:E-1.09 and D:E-2.05. The gene expression of StAR, $17 \beta-H S D$ and aromatase showed no significant difference among dietary groups.

\section{Tissue fatty acid profiles}

In all tissues of female and male fish, except the muscle of male fish, the EPA content significantly decreased $(P<0.05)$ and the DHA content significantly increased with increasing dietary DHA:EPA ratios (Tables 4-6). No significant difference was observed in DHA content in muscle of male fish (Table 6). The DHA:EPA ratios in fish tissues always significantly increased with increasing dietary DHA:EPA ratios.

Compared with ovaries, testes had lower average EPA content but higher average DHA content (Table 4). On the contrary, compared with female livers, male livers had higher average EPA content but lower average DHA content (Table 5). Testes had much lower average C18: $1 n$-9 content but higher average C16: 0 content than ovaries. In muscle, both EPA and DHA contents were higher in males than in females. The ARA contents were higher in all tissues of male fish compared with those of female fish.

Group D:E-0.68 had significantly lower $(P<0.05)$ testis C16: 0 content than group D:E-1.09. Females from group D: E-2.05 showed significantly higher $(P<0.05)$ liver C18:2n-6 content but significantly lower $(P<0.05)$ ovary C18: $1 n-7$ content compared with group D:E-0.68.

\section{Discussion}

The present study showed that both oestradiol in females and testosterone in males had the lowest concentrations in the group with the lowest dietary DHA:EPA ratio (0.68). This indicated that a low DHA:EPA ratio in the diet may have inhibitory effects on gonadal steroidogenesis in tongue sole. This inhibitory effect could partly be attributed to the high EPA levels in diets. In in vitro studies with gonadal tissues from goldfish and rainbow trout, EPA has been shown to inhibit the gonadotrophin-stimulated testosterone production ${ }^{(19,23)}$. High levels of EPA could competitively inhibit the production of ARAderived eicosanoids such as 2-series PG $\left(\mathrm{PGE}_{2}\right)$, which play important roles in gonadal steroidogenesis and maturation, and consequently inhibit the gonadal steroidogenesis and maturation $^{(14,19,20,31-35)}$. In this regard, altered EPA:ARA ratios could also modulate the gonadal steroidogenesis and maturation of fish. In this study, although the dietary ARA level was relatively constant among groups, the EPA:ARA ratio varied among diets with different DHA:EPA ratios, being 3.82, 3.14 and $2 \cdot 34$, respectively, in the three experimental diets. The highest EPA:ARA level (3.82) in the lowest DHA:EPA diet could probably exert inhibition on the steroidogenesis in tongue sole via the regulation of PG production.

With respect to ARA, although the ARA content was designed to be constant among experimental diets, a slight increase in actual dietary ARA content $(3.2,3.4$ and $3.8 \%$ of TFA) existed with decreasing dietary DHA:EPA ratios. Moderate levels of ARA and its metabolites, $\mathrm{PGE}_{2}$, have been widely demonstrated to stimulate gonadal steroidogenesis and maturation $^{(4,19,20,23,32,33,36-40)}$. A recent study in our lab investigating the effects of dietary ARA on the gonadal steroidogenesis in tongue sole showed that, compared with the group without ARA supplementation, $15.44 \%$ ARA (of TFA) in the diet 

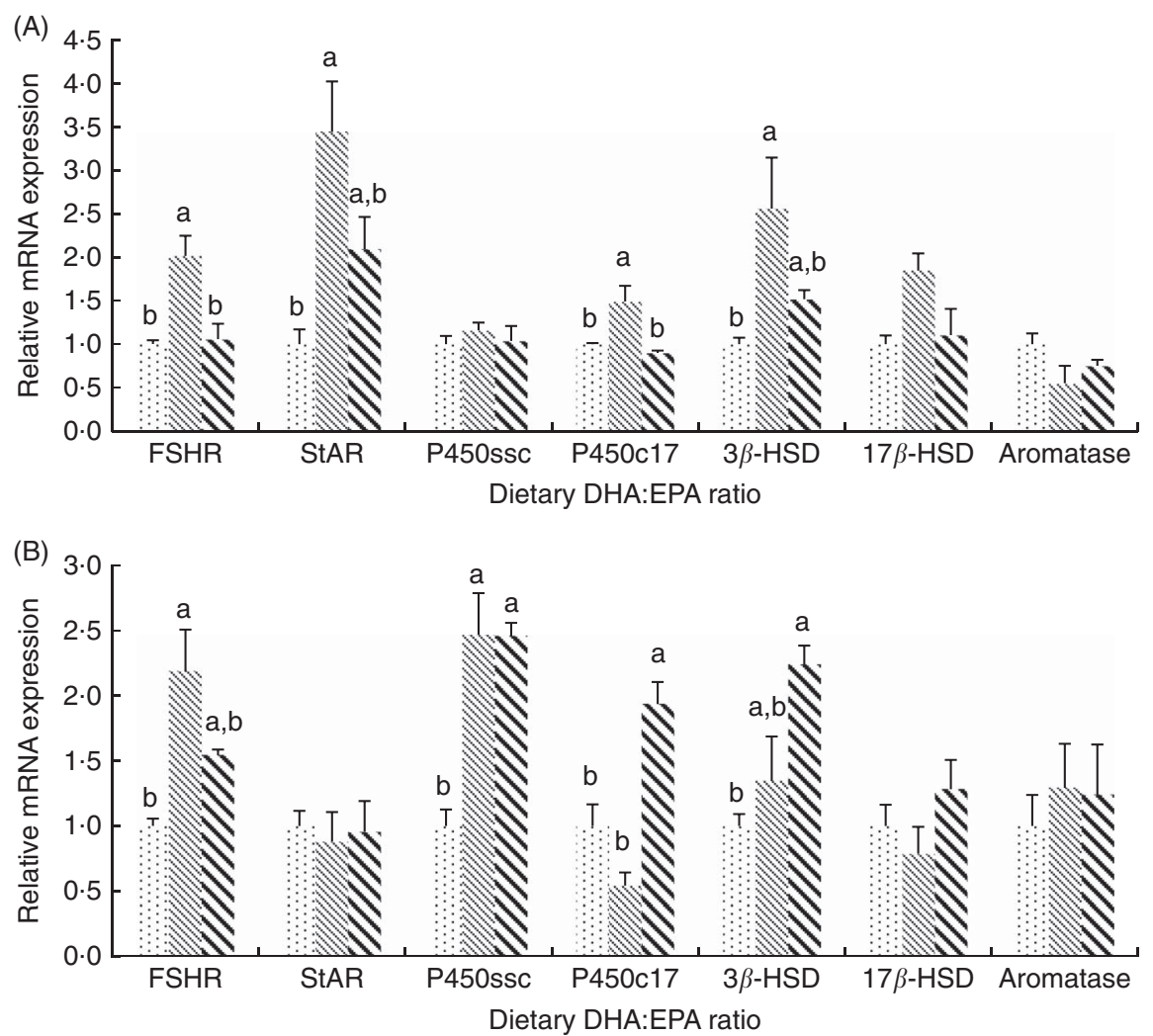

Fig. 2. Effects of dietary DHA:EPA ratios on the relative mRNA expressions of sex steroid-synthesising proteins in ovaries (A) and testes (B). Values are means of

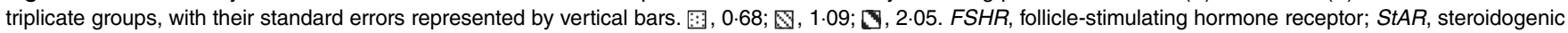

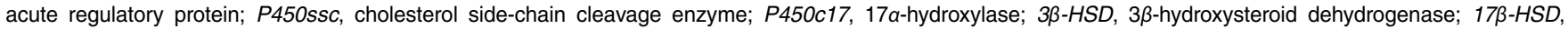
$17 \beta$-hydroxysteroid dehydrogenase. ${ }^{\text {a,b }}$ Mean values with unlike letters were significantly different $(P<0.05)$.

Table 4. Gonad fatty acid compositions of tongue sole fed the experimental diets (\% total fatty acids) ${ }^{\star}$

\begin{tabular}{|c|c|c|c|c|c|c|c|c|c|c|}
\hline \multirow[b]{2}{*}{ Fatty acids } & \multicolumn{5}{|c|}{ Female } & \multicolumn{5}{|c|}{ Male } \\
\hline & D:E-0.68 & D:E-1.09 & D:E-2.05 & Pooled SEM & $P$ & D:E-0.68 & D:E-1.09 & D:E-2.05 & Pooled SEM & $P$ \\
\hline C14:0 & 1.6 & 1.5 & 1.4 & 0.04 & 0.235 & 1.5 & 1.5 & 1.6 & 0.05 & 0.677 \\
\hline C16:0 & 16.9 & $16 \cdot 3$ & 14.5 & 0.45 & 0.064 & $21 \cdot 8^{b}$ & $25 \cdot 9^{a}$ & $23 \cdot 4^{a, b}$ & 0.67 & 0.009 \\
\hline C18:0 & 7.9 & 8.4 & 7.0 & 0.37 & 0.336 & $10 \cdot 3$ & 9.7 & $10 \cdot 2$ & 0.14 & 0.289 \\
\hline$\sum$ SFA & 26.4 & $26 \cdot 2$ & 23.0 & 0.71 & 0.071 & $33.6^{\mathrm{b}}$ & $37 \cdot 2^{a}$ & $35 \cdot 2^{a, b}$ & 0.59 & 0.009 \\
\hline C16:1n-7 & 3.1 & 2.6 & 2.6 & 0.12 & 0.025 & 1.7 & 1.8 & 1.5 & 0.14 & 0.752 \\
\hline C18: $1 n-9$ & $22 \cdot 0$ & $22 \cdot 6$ & $21 \cdot 7$ & 0.45 & 0.747 & $10 \cdot 9$ & 11.0 & 11.3 & 0.28 & 0.875 \\
\hline C18: $1 n-7$ & $3.9^{\mathrm{a}}$ & $3 \cdot 7^{\mathrm{a}, \mathrm{b}}$ & $3 \cdot 2^{b}$ & 0.13 & 0.025 & $3 \cdot 2^{\mathrm{b}}$ & $4 \cdot 6^{\mathrm{a}}$ & $3.4^{\mathrm{b}}$ & 0.24 & 0.002 \\
\hline$\Sigma$ MUFA & 29.0 & 28.9 & 27.4 & 0.45 & 0.328 & $15 \cdot 8$ & 17.4 & $16 \cdot 2$ & 0.43 & 0.328 \\
\hline C18:2n-6 & 10.9 & $11 \cdot 2$ & 11.9 & 0.22 & 0.154 & 9.7 & $10 \cdot 3$ & 9.9 & 0.16 & 0.327 \\
\hline $\mathrm{C} 20: 4 n-6$ & 2.5 & 2.4 & 2.5 & 0.08 & 0.833 & $6 \cdot 6$ & 5.5 & $6 \cdot 0$ & 0.28 & 0.317 \\
\hline$\sum n-6$ PUFA & 13.5 & $13 \cdot 6$ & 14.9 & 0.27 & 0.333 & $16 \cdot 3$ & $15 \cdot 8$ & $16 \cdot 0$ & 0.22 & 0.721 \\
\hline C18:3n-3 & 0.9 & 0.9 & 1.1 & 0.03 & 0.250 & 0.6 & 0.6 & 0.5 & 0.05 & 0.589 \\
\hline $\mathrm{C} 20: 5 n-3$ & $5 \cdot 4^{\mathrm{a}}$ & $3.9^{b}$ & $3 \cdot 6^{\mathrm{b}}$ & 0.30 & 0.003 & $5 \cdot 1^{\mathrm{a}}$ & $2 \cdot 8^{\mathrm{b}}$ & $2 \cdot 8^{\mathrm{b}}$ & 0.40 & 0.001 \\
\hline C22: $5 n-3$ & $4 \cdot 1$ & 4.0 & 4.2 & 0.06 & 0.143 & $4 \cdot 1$ & 3.5 & 3.8 & 0.13 & 0.116 \\
\hline $\mathrm{C} 22: 6 n-3$ & $11 \cdot 4^{\mathrm{b}}$ & $13 \cdot 3^{\mathrm{b}}$ & $17 \cdot 1^{\mathrm{a}}$ & 0.89 & 0.001 & $16 \cdot 5^{b}$ & $18 \cdot 8^{\mathrm{a}, \mathrm{b}}$ & $20 \cdot 4^{\mathrm{a}}$ & 0.63 & 0.009 \\
\hline$\sum n-3$ PUFA & $21 \cdot 8^{\mathrm{b}}$ & $22 \cdot 1^{\mathrm{b}}$ & $26 \cdot 0^{\mathrm{a}}$ & 0.76 & 0.011 & $26 \cdot 3$ & $25 \cdot 1$ & 27.1 & 0.39 & 0.081 \\
\hline$\sum n-3: \sum n-6$ & 1.6 & 1.6 & 1.8 & 0.05 & 0.239 & 1.6 & 1.6 & 1.7 & 0.03 & 0.403 \\
\hline DHA:EPA & $2 \cdot 1^{\mathrm{c}}$ & $3 \cdot 4^{\mathrm{b}}$ & $4.9^{a}$ & 0.43 & 0.002 & $3.3^{\mathrm{b}}$ & $6.9^{a}$ & $7 \cdot 3^{\mathrm{a}}$ & 0.69 & 0.003 \\
\hline
\end{tabular}

a,b,c Mean values within a row with unlike superscript letters were significantly different $(P<0.05)$.

* Data represent the mean of triplicate groups.

enhanced the testosterone production in males, but $5 \cdot 14 \%$ was ineffective ${ }^{(27)}$. With regard to this, inhibitory effects of the diet with the lowest DHA:EPA ratio on gonadal steroidogenesis in this study may be less attributed to the slight ARA increment.
DHA is also an important regulator of fish gonadal steroidogenesis and maturation ${ }^{(18)}$. Similar to EPA, the inhibitory effects of high levels of DHA on gonadotropin-induced steroidogenesis have also been observed in in vitro studies 
Table 5. Liver fatty acid compositions of tongue sole fed the experimental diets (\% total fatty acids) ${ }^{*}$

\begin{tabular}{|c|c|c|c|c|c|c|c|c|c|c|}
\hline \multirow[b]{2}{*}{ Fatty acids } & \multicolumn{5}{|c|}{ Female } & \multicolumn{5}{|c|}{ Male } \\
\hline & D:E-0.68 & D:E-1.09 & D:E-2.05 & Pooled SEM & $P$ & D:E-0.68 & D:E-1.09 & D:E-2.05 & Pooled SEM & $P$ \\
\hline C14:0 & 1.4 & 1.3 & 1.3 & 0.07 & 0.681 & $1 \cdot 1$ & 1.2 & 1.4 & 0.05 & 0.095 \\
\hline C16:0 & $18 \cdot 8$ & $18 \cdot 3$ & 18.0 & 0.33 & 0.640 & 18.4 & 19.9 & 19.4 & 0.43 & 0.381 \\
\hline C18:0 & $13 \cdot 6$ & $13 \cdot 4$ & $13 \cdot 1$ & 0.41 & 0.925 & $14 \cdot 3$ & $12 \cdot 8$ & $12 \cdot 8$ & 0.46 & 0.368 \\
\hline$\sum$ SFA & 33.8 & 33.0 & $32 \cdot 4$ & 0.32 & 0.209 & 33.7 & 33.9 & 33.6 & 0.37 & 0.956 \\
\hline C16:1n-7 & 1.8 & 1.8 & 1.7 & 0.15 & 0.964 & 1.5 & 1.5 & 1.3 & 0.10 & 0.716 \\
\hline C18: $1 n-9$ & 14.9 & 14.6 & $15 \cdot 4$ & 0.32 & 0.642 & 11.8 & $11 \cdot 1$ & 11.8 & 0.27 & 0.585 \\
\hline C18:1n-7 & 3.7 & 3.8 & 3.4 & 0.08 & 0.246 & $2 \cdot 5$ & $2 \cdot 6$ & $2 \cdot 0$ & 0.18 & 0.491 \\
\hline$\sum$ MUFA & $20 \cdot 4$ & $20 \cdot 2$ & $20 \cdot 6$ & 0.43 & 0.951 & $15 \cdot 7$ & $15 \cdot 2$ & $15 \cdot 1$ & 0.44 & 0.844 \\
\hline C18:2n-6 & $5.0^{\mathrm{b}}$ & $5 \cdot 3^{a, b}$ & $6 \cdot 6^{a}$ & 0.29 & 0.023 & 9.6 & 9.6 & $11 \cdot 1$ & 0.38 & 0.149 \\
\hline $\mathrm{C} 20: 4 n-6$ & 5.6 & 5.6 & 5.5 & 0.18 & 0.953 & $7 \cdot 7$ & 6.9 & 7.0 & 0.24 & 0.306 \\
\hline$\sum n-6$ PUFA & $10 \cdot 8$ & 11.0 & $12 \cdot 1$ & 0.31 & 0.107 & $17 \cdot 3$ & $16 \cdot 4$ & $18 \cdot 1$ & 0.49 & 0.428 \\
\hline C18:3n-3 & 0.3 & 0.4 & 0.4 & 0.03 & 0.189 & 0.5 & 0.4 & 0.6 & 0.05 & 0.447 \\
\hline $\mathrm{C} 20: 5 n-3$ & $6 \cdot 0^{\mathrm{a}}$ & $5 \cdot 4^{\mathrm{b}}$ & $4 \cdot 7^{\mathrm{c}}$ & 0.19 & 0.001 & $8 \cdot 6^{\mathrm{a}}$ & $6 \cdot 7^{\mathrm{b}}$ & $5 \cdot 6^{\mathrm{c}}$ & 0.44 & 0.000 \\
\hline C22: $5 n-3$ & $2 \cdot 6$ & $2 \cdot 3$ & 2.5 & 0.08 & 0.308 & 3.0 & $2 \cdot 6$ & $2 \cdot 8$ & 0.12 & 0.538 \\
\hline $\mathrm{C} 22: 6 n-3$ & $20 \cdot 1^{b}$ & $22 \cdot 4^{\mathrm{a}}$ & $22 \cdot 6^{a}$ & 0.48 & 0.013 & $16 \cdot 1^{b}$ & $18 \cdot 6^{\mathrm{a}}$ & $18 \cdot 4^{\mathrm{a}}$ & 0.45 & 0.005 \\
\hline$\sum n-3$ PUFA & $28 \cdot 9^{b}$ & $30 \cdot 4^{\mathrm{a}}$ & $30 \cdot 3^{a}$ & 0.28 & 0.019 & 28.1 & 28.1 & 27.4 & 0.25 & 0.464 \\
\hline$\sum n-3: \sum n-6$ & $2 \cdot 8$ & $2 \cdot 8$ & 2.5 & 0.07 & 0.258 & 1.6 & 1.7 & 1.5 & 0.05 & 0.333 \\
\hline DHA:EPA & $3 \cdot 4^{\mathrm{C}}$ & $4 \cdot 1^{\mathrm{b}}$ & $4 \cdot 8^{a}$ & 0.21 & 0.000 & $1.9^{\mathrm{c}}$ & $2 \cdot 8^{\mathrm{b}}$ & $3 \cdot 3^{\mathrm{a}}$ & 0.22 & 0.000 \\
\hline
\end{tabular}

a,b,c Mean values within a row with unlike superscript letters were significantly different $(P<0.05)$

* Data represent the mean of triplicate groups.

Table 6. Muscle fatty acid compositions of tongue sole fed the experimental diets (\% total fatty acids) ${ }^{\star}$

\begin{tabular}{|c|c|c|c|c|c|c|c|c|c|c|}
\hline \multirow[b]{2}{*}{ Fatty acids } & \multicolumn{5}{|c|}{ Female } & \multicolumn{5}{|c|}{ Male } \\
\hline & D:E-0.68 & D:E-1.09 & D:E-2.05 & Pooled SEM & $P$ & D:E-0.68 & D:E-1.09 & D:E-2.05 & Pooled SEM & $P$ \\
\hline C14:0 & 3.6 & $3 \cdot 2$ & $3 \cdot 1$ & 0.12 & 0.169 & $1 \cdot 7$ & 1.7 & 2.0 & 0.11 & 0.308 \\
\hline C16:0 & $22 \cdot 8$ & $21 \cdot 1$ & $22 \cdot 0$ & 0.36 & 0.125 & $21 \cdot 6$ & 24.4 & $22 \cdot 3$ & 0.63 & 0.176 \\
\hline C18:0 & $5 \cdot 6^{\mathrm{b}}$ & $6 \cdot 4^{\mathrm{a}, \mathrm{b}}$ & $6 \cdot 5^{\mathrm{a}}$ & 0.17 & 0.028 & 8.6 & $10 \cdot 6$ & 8.6 & 0.50 & 0.167 \\
\hline$\sum$ SFA & 32.0 & 30.6 & 31.6 & 0.36 & 0.280 & $31.9^{b}$ & $36 \cdot 6^{\mathrm{a}}$ & $32 \cdot 9^{a, b}$ & 0.89 & 0.045 \\
\hline C16: $1 n-7$ & $6 \cdot 2$ & $5 \cdot 2$ & $5 \cdot 2$ & 0.20 & 0.064 & 3.2 & 3.0 & 3.2 & 0.07 & 0.250 \\
\hline C18: $1 n-9$ & $16 \cdot 3$ & 13.9 & $15 \cdot 1$ & 0.59 & 0.255 & $11.6^{\mathrm{b}}$ & $12 \cdot 3^{\mathrm{b}}$ & $18 \cdot 1^{a}$ & 1.15 & 0.009 \\
\hline C18: $1 n-7$ & $3 \cdot 8^{\mathrm{a}}$ & $3 \cdot 2^{\mathrm{b}}$ & $3 \cdot 3^{\mathrm{b}}$ & 0.10 & 0.002 & $2 \cdot 6^{\mathrm{b}}$ & $2 \cdot 8^{a, b}$ & $2 \cdot 9^{a}$ & 0.06 & 0.044 \\
\hline$\sum$ MUFA & $26 \cdot 3$ & $22 \cdot 3$ & 23.6 & 0.76 & 0.066 & $17 \cdot 3^{b}$ & $18 \cdot 0^{\mathrm{b}}$ & $24 \cdot 2^{a}$ & 1.20 & 0.006 \\
\hline C18:2n-6 & 6.0 & $6 \cdot 1$ & 7.9 & 0.40 & 0.067 & 9.6 & 8.7 & 9.6 & 0.24 & 0.206 \\
\hline $\mathrm{C} 20: 4 n-6$ & $2 \cdot 1$ & $2 \cdot 8$ & 2.6 & 0.15 & 0.082 & $4 \cdot 9^{a}$ & $4 \cdot 4^{a, b}$ & $3.4^{\mathrm{b}}$ & 0.26 & 0.018 \\
\hline$\sum n-6$ PUFA & $8 \cdot 1$ & 8.9 & 10.5 & 0.46 & 0.074 & $14.6^{\mathrm{a}}$ & $13 \cdot 1^{\mathrm{b}}$ & $13 \cdot 0^{\mathrm{b}}$ & 0.28 & 0.009 \\
\hline C18:3n-3 & 0.9 & 0.7 & 0.7 & 0.04 & 0.061 & 0.6 & 0.6 & 0.7 & 0.03 & 0.413 \\
\hline $\mathrm{C} 20: 5 n-3$ & $4 \cdot 0^{\mathrm{a}}$ & $3.9^{\mathrm{a}}$ & $3.0^{\mathrm{b}}$ & 0.21 & 0.049 & $6.5^{a}$ & $4 \cdot 6^{\mathrm{b}}$ & $3 \cdot 5^{c}$ & 0.44 & 0.000 \\
\hline $\mathrm{C} 22: 5 n-3$ & 4.6 & 4.9 & 4.7 & 0.14 & 0.597 & 4.2 & 3.4 & 4.0 & 0.20 & 0.267 \\
\hline $\mathrm{C} 22: 6 n-3$ & $14 \cdot 4^{\mathrm{b}}$ & $18 \cdot 2^{a}$ & $17 \cdot 6^{\mathrm{a}}$ & 0.61 & 0.000 & $18 \cdot 1$ & 18.9 & $19 \cdot 1$ & 0.57 & 0.810 \\
\hline$\sum n-3$ PUFA & $23 \cdot 7^{\mathrm{b}}$ & $27.8^{a}$ & $26 \cdot 0^{\mathrm{a}, \mathrm{b}}$ & 0.65 & 0.009 & 29.5 & 27.5 & 27.3 & 0.69 & 0.398 \\
\hline$\sum n-3: \sum n-6$ & 2.9 & 3.2 & 2.5 & 0.15 & 0.138 & 2.0 & $2 \cdot 1$ & $2 \cdot 1$ & 0.06 & 0.865 \\
\hline DHA:EPA & $3.7^{\mathrm{b}}$ & $4 \cdot 6^{\mathrm{b}}$ & $6 \cdot 0^{\mathrm{a}}$ & 0.36 & 0.002 & $2 \cdot 8^{\mathrm{c}}$ & $4 \cdot 1^{\mathrm{b}}$ & $5 \cdot 4^{\mathrm{a}}$ & 0.41 & 0.002 \\
\hline
\end{tabular}

a,b,c Mean values within a row with unlike superscript letters were significantly different $(P<0.05)$.

* Data represent the mean of triplicate groups.

with fish gonadal tissues ${ }^{(19,23)}$. Besides steroidogenesis, the gonadotropin-induced oocyte maturation in marine teleost (European sea bass Dicentrarchus labrax) was also observed to be inhibited by high levels of $\mathrm{DHA}^{(4)}$. The inhibitory effects of high DHA levels could partly contribute to the inhibitory effects of the highest DHA:EPA ratio on oestradiol production in female tongue sole in this study. The group with highest DHA:EPA (2.05) showed a decrease in oestradiol production in females compared with the group with the moderate DHA:EPA ratio (1.09). However, in testes of male tongue sole, the highest testosterone production was observed in the group with the highest DHA:EPA ratio. This indicated that, compared with females, male tongue sole may require more DHA and less EPA for the gonadal steroidogenesis. Although in vitro studies stated above showed the inhibitory effects of high levels of both EPA and DHA on gonadotropininduced steroidogenesis ${ }^{(19,23)}$, a very high level of DHA significantly stimulated the PGE production in testis cell of European sea bass at all the times of incubation ${ }^{(20)}$. To some extent, this might provide a clue for the relatively high DHA requirement in steroidogenesis and maturation of male fish. A significantly positive correlation between testis DHA content and serum testosterone concentrations has been reported in mature male European eel (Anguilla anguilla) ${ }^{(18)}$, indicating that DHA might play positive roles in testosterone synthesis. 
The difference in effective DHA:EPA ratio between female and male tongue sole was in good accordance with the different accumulation of DHA and EPA between ovaries and testes. Testes had more DHA (average $18.5 v .13 .9 \%$ of TFA) but less EPA (average $3.6 v .4 .3 \%$ ) accumulation than ovaries. Interestingly, in the liver of tongue sole, a reverse observation was made; that is, males had less DHA (average 17.7 v. $21.7 \%$ ) but more EPA (average 6.9 v. 5.4\%) than females. Preferable LC-PUFA were probably transferred to gonads from other tissues during maturation to meet the reproductive requirements ${ }^{(41)}$. Baeza et al. ${ }^{(17)}$ reported that in the testis of European eel all primary LC-PUFA, that is, DHA, EPA and ARA, remained constant during the maturation process. De novo synthesis of EPA and DHA in the liver and probable subsequent transfer of them to the testis was also observed in that study. Differently, Japanese eel (Anguilla japonica) testes seemed to have a higher preference for $\mathrm{EPA}^{(42)}$. In addition, in the muscle of tongue sole the contents of both DHA and EPA were higher in males than in females. Higher muscle LC-PUFA contents in males than in females were also observed in mountain trout (Salmo trutta macrostigma) $^{(43)}$. The sex-specific fatty acid preference in fish tissues must be closely correlated with the sex-specific bio-functions of fatty acids, and this could be regulated by the different sex hormone secretion between female and male fish ${ }^{(18,44-47)}$

Besides the sex-specific effects of DHA:EPA, another interesting observation of this study was that the DHA:EPA ratio inducing the highest sex steroid production in both females and males was $>1 \cdot 0$. This indicated that DHA may be superior to EPA in promoting fish steroid hormone synthesis. Very little information has been available about the relative effectiveness of DHA and EPA in regulating fish steroidogenesis, although several in vivo studies with fish species such as gilthead seabream (Sparus aurata), silver pomfret (Pampus argenteus) and European eel have investigated the effects of total LC-PUFA or $n-3$ LC-PUFA on sex steroid production ${ }^{(24-26)}$. A feeding trial with Siberian sturgeon (Acipenser baeri) showed that serum oestradiol was higher in females fed the diet with a DHA:EPA ratio of 1.9:1 compared with the ratio of $1: 1.9^{(22)}$, providing another evidence for the superiority of DHA to EPA in inducing sex steroid production. Similar to steroidogenesis results, some studies have also indicated the superior effect of DHA to EPA on other reproductive parameters. In a study with European sea bass, the PUFA-enriched diets with higher DHA content but lower EPA content induced the better-quality eggs and larvae (although reduced the spawning parameters) compared with the control diet ${ }^{(48)}$, whereas another study with male European sea bass showed that the wet diet containing a higher EPA content resulted in lower spermiation performance and lower sperm quality as compared with the PUFA-enriched diet with a lower EPA content ${ }^{(3)}$. However, contradictory results were also observed in other fish species. A study with domesticated common sole (Solea solea) breeders showed that egg EPA concentration was positively correlated with larval viability, but egg DHA concentration was negatively correlated with hatching rate and larval viability ${ }^{(49)}$. To date, the relative effects of DHA and EPA on steroidogenesis and other reproductive parameters is highly unknown, and more future studies are needed.
Regarding the regulation of sex steroid-synthesising proteins by dietary DHA:EPA ratios, in tongue sole ovaries the gene expression of FSHR, StAR, P450c17 and 3 $\beta$-HSD was significantly influenced by dietary treatments; however, the gene expression of $17 \beta-H S D$ and aromatase was not significantly different among experimental groups. The effects of diets on $17 \beta-H S D$ and aromatase may be masked by the endogenous inhibition of these enzymes in the time point of sampling. Tongue sole has group-synchronous ovarian development. Shifts in gonadal steroidogenesis in the group-synchronous gonadal development have been observed in several fish species such as European sea bass, rainbow trout (Oncorhynchus mykiss) and striped bass (Morone saxatilis) ${ }^{(50-53)}$. At the very beginning of ovulation, during which the samples were obtained in the present study, maturation-inducing progestagens may reach peaks, whereas the oestradiol production may already be decreasing ${ }^{(53)}$. Inhibition of $17 \beta-H S D$ and aromatase might be involved in the endogenous down-regulation of oestradiol production at this time point, considering that these two enzymes are two of the most important and rate-limiting enzymes in oestradiol synthesis.

In the testes, although dietary DHA:EPA ratios influenced gene expressions of several proteins such as FSHR, P450sSC, $P 450 c 17$ and $3 \beta-H S D$, only the regulation of $3 \beta-H S D$ correlated well with the testosterone concentration results. This was in agreement with our previous studies investigating the steroidogenesis-regulating effects of ARA in this fish ${ }^{(27)}$. These results indicate that $3 \beta-H S D$, which converts pregnenolones to progesterones, may play a key role in the regulation of testosterone synthesis by fatty acids ${ }^{(54,55)}$. Peñaranda et al ${ }^{(56)}$ have reported the gene expression of cyp11a1 (P450ssc) and cyp17-I (P450c17), which are important enzymes initiating the testosterone synthetic pathway, correlated well with the testosterone synthesis during the maturation of European eel testis. However, in the present study, only a general positive correlation was observed between testosterone production and P450ssc or P450c17 gene expression. As in ovaries, the aromatase gene expression in testes was also not influenced by dietary DHA: EPA ratio, but this may be related to the fact that the aromatase mRNA was less abundant in the testis ${ }^{(57)}$

Regarding the difference between sexes in effective DHA: EPA ratio inducing the highest gene expression of steroidogenic proteins, the results were consistent with the steroid concentration results for some proteins such as FSHR, StAR, $P 450 c 17$ and $3 \beta-H S D$ in ovaries and P450c17 and $3 \beta-H S D$ in testes; that is, the DHA:EPA ratio of 1.09 induced the highest gene expressions in ovaries, whereas the ratio of 2.05 induced the highest values in testes. This, to some extent, confirmed that males may require more DHA and less EPA than females for steroid synthesis. The difference in gonadal steroidogenesis between males and females may contribute to the sex-specific modulation of sex steroid-synthesising proteins by dietary fatty acids; however, very little information has been available about the difference in steroidogenesis between ovaries and testes of this fish. The commonly occuring sex reversal in juveniles of this fish makes this issue more complicated ${ }^{(58,59)}$. In this study, the gene expression of StAR, the rate-limiting transport protein translocating cholesterol from the outer mitochondrial 
membrane to the inner mitochondrial P450scc site, was regulated by experimental diets in females but not in males. This difference could be related to the fact that ovaries and testes may use cholesterol substrate supplied in different ways ${ }^{(60)}$. In mammals, for the steroid synthesis, the ovaries preferentially use cholesterol supplied from plasma lipoprotein via the scavenger receptor class B type I-mediated endocytic pathway, whereas the testicular Leydig cells rely heavily on the use of endogenously synthesised cholesterol ${ }^{(61-63)}$. In this regard, the difference in cholesterol substrate abundance between ovaries and testes may interfere with regulation of StAR by fatty acids. Contrary to StAR, the gene expression of P450sSC was regulated by diets in males but not in females. This may be related to the fact that the gene expression of P450ssc (cyp11a1) correlates better with testosterone production ${ }^{(56)}$

With respect to the tissue fatty acid compositions, besides DHA and EPA, ARA also differently accumulated in the females and males, as observed in our previous studies with this fish ${ }^{(27)}$. Males had much higher ARA contents than females in all tissues analysed. Male average $v$. female average was $6.0 v .2 .5 \%$ (of TFA), $7.2 v \cdot 5.6 \%$ and $4.2 v .2 .5 \%$ in gonad, liver and muscle, respectively. Several studies have indicated that ARA was metabolised differently in male and female fish and suggest that ARA may be more important for the reproductive success of males ${ }^{(40,64)}$. Higher $n-6: n-3$ PUFA ratios have also been shown to be more beneficial to male fish than to female fish ${ }^{(3,13,65)}$

Besides the LC-PUFA, oleic acid (C18 : 1n-9, OA) was another important fatty acid with different accumulation between female and male tongue sole. For all tissues, females had obvious high OA contents than males. Female average $v$. male average for OA was $22 \cdot 1 v \cdot 11 \cdot 1 \%$ (of TFA), $15 \cdot 0 v \cdot 11 \cdot 6 \%$ and $15 \cdot 1$ v. $14.0 \%$ in gonad, liver and muscle, respectively. Gonad had higher OA content variation between sexes (content in ovary is two times that in testis) than liver and muscle, and on the other hand ovaries had the highest OA content among all the tissues. OA is a major energy source during egg and larval development ${ }^{(66)}$. Significant positive correlations between the OA content of fish eggs and egg viability or hatching percentages have been observed in gilthead seabream broodstock ${ }^{(67)}$. Therefore, the high OA accumulation in tongue sole ovaries must be a preparation for the energy demand in egg and larval development. Different from OA, palmitic acid (C16:0, PA), another important energy fatty acid, had no significant difference between sexes in the liver and muscle contents. However, testes had much higher PA content than ovaries (average $23.7 v$. $15.9 \%$ of TFA). De novo synthesis of PA has been observed in the liver of male European eel during spermatogenesis ${ }^{(17)}$. PA might have special physiological or energetic roles in the testosterone synthesis or spermatogenesis in male fish, but the precise mechanisms need to be elucidated by future studies.

In conclusion, the present results suggest that the dietary DHA:EPA ratio, possibly combined with the dietary EPA:ARA ratio, differentially regulated sex steroid hormone synthesis in mature female and male tongue soles. Females seemed to require more EPA but less DHA than males for gonadal steroidogenesis. The LC-PUFA accumulations in fish gonads and the response of gene expressions of sex steroid-synthesising proteins to dietary DHA:EPA confirmed the regulation of sex steroid hormone production by dietary DHA:EPA.

\section{Acknowledgements}

The authors thank Y. M. Yang and Q. H. Li for their help in fish rearing.

This work was supported by the National Natural Science Foundation of China (31402309), Central Public-interest Scientific Institution Basal Research Fund, YSFRI, CAFS (20603022017018) and a Grant from the Modern Agro-industry Technology Research System (CARS-50-G08, Government of China).

H. X. and M. L. designed the study. H. X. analysed the data and wrote the manuscript. L. C. carried out the feeding trial and the real-time PCR. Y. W. and Y. Z. were involved in the realtime PCR and the fatty acid analysis. All the authors read and approved the final manuscript.

The authors declare that there are no conflicts of interest.

\section{References}

1. Gulliver CE, Friend MA, King BJ, et al. (2012) The role of omega-3 polyunsaturated fatty acids in reproduction of sheep and cattle. Anim Reprod Sci 131, 9-22.

2. Elis S, Freret S, Desmarchais A, et al. (2016) Effect of a long chain $n$-3 PUFA-enriched diet on production and reproduction variables in Holstein dairy cows. Anim Reprod Sci 164, 121-132.

3. Asturiano JF, Sorbera LA, Carrillo M, et al. (2001) Reproductive performance in male European sea bass (Dicentrarchus labrax, L.) fed two PUFA-enriched experimental diets: a comparison with males fed a wet diet. Aquaculture 194, 173-190.

4. Sorbera LA, Asturiano JF, Carrillo M, et al. (2001) Effects of polyunsaturated fatty acids and prostaglandins on oocyte maturation in a marine teleost, the European sea bass (Dicentrarchus labrax). Biol Reprod 64, 382-389.

5. Furuita H, Tanaka H, Yamamoto T, et al. (2000) Effects of $n-3$ HUFA levels in broodstock diet on the reproductive performance and egg and larval quality of the Japanese flounder, Paralichthys olivaceus. Aquaculture 187, 387-398.

6. Almansa E, Martín MV, Cejas JR, et al. (2001) Lipid and fatty acid composition of female gilthead seabream during their reproductive cycle: effects of a diet lacking n-3 HUFA. J Fish Biol 59, 267-286.

7. Izquierdo MS, Fernández-Palacios H \& Tacon AGJ (2001) Effect of broodstock nutrition on reproductive performance of fish. Aquaculture 197, 25-42.

8. Watanabe T \& Vassallo-Agius R (2003) Broodstock nutrition research on marine finfish in Japan. Aquaculture 227, 35-61.

9. Rodríguez-Barreto D, Jerez S, Cejas JR, et al. (2012) Comparative study of lipid and fatty acid composition in different tissues of wild and cultured female broodstock of greater amberjack (Seriola dumerili). Aquaculture 360-361, 1-9.

10. Beirão J, Soares F, Pousão-Ferreira P, et al. (2015) The effect of enriched diets on Solea senegalensis sperm quality. Aquaculture 435, 187-194.

11. Butts IAE, Baeza R, Støttrup JG, et al. (2015) Impact of dietary fatty acids on muscle composition, liver lipids, milt composition and sperm performance in European eel. Comp Biochem Physiol 183A, 87-96.

12. Bell JG, Farndale BM, Bruce MP, et al. (1997) Effects of broodstock dietary lipid on fatty acid compositions of eggs 
from sea bass (Dicentrarchus labrax). Aquaculture 149, 107-119.

13. Bruce M, Oyen F, Bell G, et al. (1999) Development of broodstock diets for the European sea bass (Dicentrarchus labrax) with special emphasis on the importance of $n-3$ and $\mathrm{n}-6$ highly unsaturated fatty acid to reproductive performance. Aquaculture 177, 85-97.

14. Tocher DR (2003) Metabolism and functions of lipids and fatty acids in teleost fish. Rev Fish Sci 11, 107-184.

15. McKenna NJ (2015) Gonadal Steroid Action. In Knobil and Neill's Physiology of Reproduction, 4th ed. pp. 313-333 [T Plant and A Zeleznik, editors]. San Diego, CA: Academic Press.

16. Ogino $Y$, Sato $T \&$ Iguchi $T$ (2016) Gonadal Steroids. In Handbook of Hormones, 1st ed. pp. 504-506 [Y Takei, H Ando and K Tsutsui, editors]. San Diego, CA: Academic Press.

17. Baeza R, Mazzeo I, Vílchez MC, et al. (2014) Effect of thermal regime on fatty acid dynamics in male European eels (Anguilla anguilla) during hormonally-induced spermatogenesis. Aquaculture 430, 86-97.

18. Baeza R, Peñaranda DS, Vílchez MC, et al. (2015) Exploring correlations between sex steroids and fatty acids and their potential roles in the induced maturation of the male European eel. Aquaculture 435, 328-335.

19. Wade MG, Van Der Kraak G, Gerrits MF, et al. (1994) Release and steroidogenic actions of polyunsaturated fatty acids in the goldfish testis. Biol Reprod 51, 131-139.

20. Asturiano JF, Sorbera LA, Zanuy S, et al. (2000) Effects of polyunsaturated fatty acids and gonadotropin on prostaglandin series $\mathrm{E}$ production in a primary testis cell culture system for the European sea bass. J Fish Biol 57, 1563-1574.

21. Castellano CA, Audet I, Laforest JP, et al. (2011) Fish oil diets alter the phospholipid balance, fatty acid composition, and steroid hormone concentrations in testes of adult pigs. Theriogenology 76, 1134-1145.

22. Luo L, Ai L, Li T, et al. (2015) The impact of dietary DHA/EPA ratio on spawning performance, egg and offspring quality in Siberian sturgeon (Acipenser baeri). Aquaculture 437, $140-145$

23. Mercure F \& Van Der Kraak D (1995) Inhibition of gonadotropin-stimulated ovarian steroid production by polyunsaturated fatty acids in teleost fish. Lipids 30, 547-554.

24. Wassef EA, Wahbi OM \& Shalaby SH (2012) Effects of dietary vegetable oils on liver and gonad fatty acid metabolism and gonad maturation in gilthead seabream (Sparus aurata) males and females. Aquacult Int 20, 255-281.

25. Peng S, Gao Q, Shi Z, et al. (2015) Effect of dietary n-3 LC-PUFAs on plasma vitellogenin, sex steroids, and ovarian steroidogenesis during vitellogenesis in female silver pomfret (Pampus argenteus) broodstock. Aquaculture $\mathbf{4 4 4}$, 93-98.

26. da Silva F, Støttrup JG, Kjørsvik E, et al. (2016) Interactive effects of dietary composition and hormonal treatment on reproductive development of cultured female European eel, Anguilla. Anim Reprod Sci 171, 17-26.

27. Xu H, Cao L, Zhang Y, et al. (2017) Dietary arachidonic acid differentially regulates the gonadal steroidogenesis in the marine teleost, tongue sole (Cynoglossus semilaevis), depending on fish gender and maturation stage. Aquaculture 468, 378-385.

28. $\mathrm{Xu} \mathrm{H}$, Mu Y, Zhang $\mathrm{Y}$, et al. (2016) Graded levels of fish protein hydrolysate in high plant diets for turbot (Scophthalmus maximus): effects on growth performance and lipid accumulation. Aquaculture 454, 140-147.

29. Xu H, Dong X, Ai Q, et al. (2014) Regulation of tissue LCPUFA contents, $\Delta 6$ fatty acyl desaturase (FADS2) gene expression and the methylation of the putative FADS2 gene promoter by different dietary fatty acid profiles in Japanese seabass (Lateolabrax japonicus). PLOS ONE 9, e87726.

30. Livak KJ \& Schmittgen TD (2001) Analysis of relative gene expression data using real-time quantitative PCR and the $2^{-\Delta \Delta C T}$ method. Methods 25, 402-408.

31. Stacey NE \& Goetz FW (1982) Role of prostaglandins in fish reproduction. Can J Fish Aquat Sci 39, 92-98.

32. Van Der Kraak G \& Chang JP (1990) Arachidonic acid stimulates steroidogenesis in goldfish preovulatory ovarian follicles. Gen Comp Endocrinol 77, 221-228.

33. Wade MG \& Van Der Kraak G (1993) Arachidonic acid and prostaglandin $\mathrm{E}_{2}$ stimulate testosterone production by goldfish testis in vitro. Gen Comp Endocrinol 90, 109-111.

34. Mercure F \& Van Der Kraak G (1996) Mechanisms of action of free arachidonic acid on ovarian steroid production in the goldfish. Gen Comp Endocrinol 102, 130-140.

35. Sargent JR, Bell JG \& Tocher DR (2002) The lipids. In Fish Nutrition, 3rd ed. pp. 181-257 [JE Halver and RW Hardy, editors]. San Diego, CA: Academic Press.

36. López-Ruiz MP, Choi MSK, Rose MP, et al. (1992) Direct effects of arachidonic acid on protein kinase $\mathrm{C}$ and LH-stimulated steroidogenesis in rat Leydig cells; evidence for tonic inhibitory control of steroidogenesis by protein kinase $C$. Endocrinology 130, 1122-1130.

37. Lister AL \& Van Der Kraak D (2008) An investigation into the role of prostaglandins in zebrafish oocyte maturation and ovulation. Gen Comp Endocrinol 159, 46-57.

38. Baeza R, Mazzeo I, Vílchez MC, et al. (2015) Relationship between sperm quality parameters and the fatty acid composition of the muscle, liver and testis of European eel. Comp Biochem Physiol 181A, 79-86.

39. Norambuena F, Estevéz A, Mañanós E, et al. (2013) Effects of graded levels of arachidonic acid on reproductive physiology of Solea sole (Solea senegalensis): fatty acid composition, prostaglandins and steroid levels in the blood of broodstock bred in captivity. Gen Comp Endocrinol 191, 92-101.

40. Norambuena F, Estévez A, Sánchez-Vázquez FJ, et al. (2012) Self-selection of diets with different contents of arachidonic acid by Senegalese sole (Solea senegalensis) broodstock. Aquaculture 365, 198-205.

41. Huang X, Yin Y, Shi Z, et al. (2010) Lipid content and fatty acid composition in wild-caught silver pomfret (Pampus argenteus) broodstocks: effects on gonad development. Aquaculture 310, 192-199.

42. Rupia EJ, Shen J, Wu J, et al. (2014) Effect of hormone injection frequency on the lipid content and fatty acid compositions in gonad, muscle and liver of Anguilla japonica during artificial maturation. Aquacult Int 22, 1105-1120.

43. Akpinar MA, Görgün S \& Akpinar AE (2009) A comparative analysis of the fatty acid profiles in the liver and muscles of male and female Salmo trutta macrostigma. Food Chem 112, 6-8.

44. Alessandri J-M, Extier A, Astorg P, et al. (2009) Métabolisme des acides gras oméga-3: différences entre hommes et femmes. Nutr Clin Métab 23, 55-66.

45. Alessandri JM, Extier A, Algubory KH, et al. (2012) Influence of gender on DHA synthesis: the response of rat liver to low dietary $\alpha$-linolenic acid evidences higher $\omega 3 \Delta$ 4-desaturation index in females. Eur J Nutr 51, 199-209.

46. McNamara RK, Able J, Jandacek R, et al. (2008) Gender differences in rat erythrocyte and brain docosahexaenoic acid composition: role of ovarian hormones and dietary omega-3 fatty acid composition. Psychoneuroendocrinology $\mathbf{3 4}$, 532-539.

47. Marks KA, Kitson AP \& Stark KD (2013) Hepatic and plasma sex differences in saturated and monounsaturated fatty acids 
are associated with differences in expression of elongase 6, but not stearoyl-CoA desaturase in Sprague-Dawley rats. Genes Nutr 8, 317-327.

48. Asturiano JF, Zanuy S, Ramos J, et al. (2006) Spawning performance and eggs and larvae quality in European sea bass (Dicentrarchus labrax L.) broodstock fed with krill or PUFA enriched diets. J Anim Vet Adv 5, 163-169.

49. Parma L, Bonaldo A, Pirini M, et al. (2015) Fatty acid composition of eggs and its relationships to egg and larval viability from domesticated common sole (Solea solea) breeders. Reprod Domest Anim 50, 186-194.

50. King WV, Berlinsky DL \& Sullivan CV (1994) Hormonal regulation of final maturation of striped bass oocytes in vitro. Gen Comp Endocrinol 96, 223-233.

51. Prat F, Sumpter JP \& Tyler CR (1996) Validation of radioimmunoassays for two salmon gonadotropins (GTH I and GTH II) and their plasma concentrations throughout the reproductivecycle in male and female rainbow trout (Oncorbynchus mykiss). Biol Reprod 54, 1375-1382.

52. Mylonas CC, Scott AP \& Zohar Y (1997) Plasma gonadotropin II, sex steroids, and thyroid hormones in wild striped bass (Morone saxatilis) during spermiation and final oocyte maturation. Gen Comp Endocrinol 108, 223-236.

53. Asturiano JF, Sorbera LA, Ramos J, et al. (2002) Groupsynchronous ovarian development, ovulation and spermiation in the European sea bass (Dicentrarchus labrax L.) could be regulated by shifts in gonadal steroidogenesis. Sci Mar 66, 273-282.

54. Wang XJ \& Stocco DM (2005) The decline in testosterone biosynthesis during male aging: a consequence of multiple alterations. Mol Cell Endocrinol 238, 1-7.

55. Midzak AS, Chen H, Papadopoulos V, et al. (2009) Leydig cell aging and the mechanisms of reduced testosterone synthesis. Mol Cell Endocrinol 299, 23-31.

56. Peñaranda DS, Morini M, Tveiten $H$, et al. (2016) Temperature modulates testis steroidogenesis in European eel. Comp Biochem Physiol 197A, 58-67.

57. Deng S, Chen S, Xu J, et al. (2009) Molecular cloning, characterization and expression analysis of gonadal P450 aromatase in the half-smooth tongue-sole, Cynoglossus semilaevis. Aquaculture 287, 211-218.

58. Shao C, Li Q, Chen S, et al. (2014) Epigenetic modification and inheritance in sexual reversal of fish. Genome Res 24, 604-615.

59. Jiang L \& Li H (2017) Single locus maintains large variation of sex reversal in half-smooth tongue sole (Cynoglossus semilaevis). G3 (Bethesda) 7, 583-589.

60. Hu J, Zhang ZH, Shen WJ, et al. (2010) Cellular cholesterol delivery, intracellular processing and utilization for biosynthesis of steroid hormones. Nutr Metab 7, 1-25.

61. Azhar S \& Reaven E (2002) Scavenger receptor class BI and selective cholesteryl ester uptake: partners in the regulation of steroidogenesis. Mol Cell Endocrinol 195, 1-26.

62. Azhar S, Leers-Sucheta S \& Reaven E (2003) Cholesterol uptake in adrenal and gonadal tissues: the SR-BI and 'selective' pathway connection. Front Biosci 8, s998-s1029.

63. Goldstein JL \& Brown MS (2009) The LDL receptor. Arterioscler Thromb Vasc Biol 29, 431-438.

64. Norambuena F, Morais S, Estévez A, et al. (2013) Dietary modulation of arachidonic acid metabolism in Senegalese sole (Solea senegalensis) broodstock reared in captivity. Aquaculture 372, 80-88.

65. Cerdá J, Zanuy S, Carrillo M, et al. (1995) Short- and long-term dietary effects on female sea bass (Dicentrarchus labrax): seasonal changes in plasma profiles of lipids and sex steroids in relation to reproduction. Comp Biochem Physiol 111C, 83-91.

66. Van Der Meeren T, Klungsoyr I, Wilbelmsen S, et al. (1991) Fatty acid composition of unfed and growing cod larvae, Gadus morbua L., feeding on natural plankton in large enclosures. In Physiological and Biochemical Aspects of Fish Development, pp. 34-35 [BT Walther and HJ Fyhn, editors]. Bergen: University of Bergen.

67. Fernández-Palacios H, Izquierdo M, Robaina L, et al. (1997) The effect of dietary protein and lipid from squid and fish meals on egg quality of broodstock for gilthead seabream. Aquaculture 148, 233-246.

(

